\title{
FICCIONES ARGENTINAS DESDE EL GÉNERO: UN ARCHIVO VIVO
}

\author{
ARGENTINE FICTIONS FROM THE GENDER: A LIVE LIFE
}

Florencia ANGILLETTA Universidad de Buenos Aires / CONICET

florenciangilletta@gmail.com

Resumen: La política argentina posterior al retorno democrático, desde 1983, está atravesada por la presencia de las mujeres. Un año después de la reforma constitucional, desde 1994, las ficciones argentinas leídas «desde el género», integran esta conmoción y construyen espacios a modo de mapas, de nuevas formas de intimidad y de los vínculos de amistad entre mujeres. ¿Cuáles son las formas en que las novelas intervienen en esta habitabilidad? ¿Qué imaginaciones exploran algunas narraciones sobre estos nuevos lugares? En el encuentro entre literatura y vida pueden leerse los maneras en que las novelas procesan y modifican las lenguas, espacios y afectos de mujeres en la Argentina democrática, a partir de la precursora El Affair Skeffington (1992), de María Moreno, seguida por una primera zona de los tempranos noventa con Bajar es lo peor (1995), de Mariana Enríquez, y El fin de la historia (1996), de Liliana Heker, junto a una segunda zona en los 2000 con Me encantaría que gustes de mí (2005), de Dalia Rosetti, seudónimo de Fernanda Laguna, y ¿Vos me querés a mí? (2007), de Romina Paula.

Palabras clave: género; mujeres; afecto; literatura argentina.

Abstract: The politics of Argentina after the democratic return, since 1983, is crossed by the presence of women. One year after the constitutional reform, since 1994, Argentine fictions read «from the gender», integrate this commotion and construct spaces as maps, new forms of intimacy and friendship links between women. What are the ways in which novels intervene in this habitability? What imaginings explore some narrations about these new places? In the encounter between literature and life it's possible to read the ways in which novels process and modify the languages, spaces and affections of women in democratic Argentina starting with the precursor El Affair Skeffington (1992), by María Moreno, followed by a first zone of the early nineties with Bajar es lo peor (1995), by Mariana Enríquez, and El fin de la historia (1996), by Liliana Heker, next to a second zone in the 2000s with Me encantaría que gustes de mí (2005), by Dalia Rosetti, pseudonym of Fernanda Laguna, and ¿Vos me querés a mí? (2007), by Romina Paula.

Keywords: gender; women; affection; argentine literature. 


\section{$\mathbf{L}$}

\section{enguas y lugares}

Las lenguas de las mujeres transformaron las políticas — del Estado, de la economía, del arteen las últimas décadas. Las ficciones argentinas, leídas «desde el género», reconfiguran esta conmoción de los espacios. El colectivo Lobo Suelto, que desde la publicación lobosuelto.com interviene sobre arte y vida social, señala que la política argentina posterior al retorno de la institucionalidad democrática, desde 1983, está atravesada por la presencia de las mujeres: la lucha por los derechos humanos de las Madres y Abuelas de Plaza de Mayo, el asesinato en 1997 - aún impune- de la trabajadora Teresa Rodríguez en las primeras manifestaciones sociales en Cutral-có (Neuquén), que la transforman en un símbolo del movimiento piquetero, y la visibilidad de los cuerpos configurados por el género, desde 2015, a partir de las convocatorias «Ni Una Menos».

La democracia no es tan sólo un régimen que se distingue por una distribución de los poderes —legislativo, ejecutivo y judicial一, sino por un «reparto determinado de lo sensible» (Rancière, 1998). En estas vidas formadas por nuevas distribuciones estéticas, las mujeres empezaron a habitar de otras maneras los lugares de la democracia. ¿Cuáles son las formas en que las novelas intervienen en esta habitabilidad? ¿Qué imaginaciones exploran algunas narraciones sobre los nuevos espacios para las mujeres? En el encuentro entre literatura y vida pueden leerse los modos en que las novelas procesan y modifican las lenguas, espacios y afectos de mujeres en la Argentina democrática: la precursora El Affair Skeffington (1992), de María Moreno, es seguida por una primera zona de los tempranos noventa Bajar es lo peor (1995), de Mariana Enríquez, y El fin de la historia (1996), de Liliana Heker; los 2000 inauguran una segunda zona con Me encantaría que gustes de mí (2005), de Dalia Rosetti, seudónimo de Fernanda Laguna, y ¿Vos me querés a mí? (2007), de Romina Paula.

Para pensar las narraciones en estos cortes el año 1994 es clave: recién hacia esa fecha las mujeres argentinas consiguen mayor igualdad ciudadana con la reforma constitucional que eleva a rango jurídico las normativas internacionales en «defensa de la mujer» ${ }^{1}$, en línea con los derechos adquiridos apenas uno años antes, la «ley de cupos» para la actividad política desde 1991, y la patria potestad compartida desde 1985. Mientras los cuerpos se precarizan, los códigos movilizan las fronteras del reconocimiento. Hasta aquel momento, en pleno auge del neoliberalismo, en la historia de Occidente sólo había dos presidentas electas y aún no existía la figura legal de «femicidio», que alude al asesinato de mujeres por el hecho de serlo.

Un año después de la reforma de 1994, las ficciones argentinas «desde el género» forman parte de esta conmoción, de este régimen de lenguas y afectos, escrituras que intervienen sobre estas

\footnotetext{
${ }^{1}$ En Argentina, para que esta igualdad sea en efecto plena, aún está pendiente, entre otros derechos, la despenalización y legalización del aborto. Al respecto, véase: abortolegal.com.ar.
} 
transformaciones y son afectadas por la vida, por formas alternativas de aproximarse a la dimensión pasional o emocional a partir de su rol en el ámbito público (Macón, 2015).

¿Mujeres en el ámbito público o mujeres «públicas»? La «ideología de la domesticidad» (Scott, 1993) condensa una división «moderna» entre trabajos, valores y géneros: el varón es quien debe ocuparse de la producción en el espacio público y la mujer, de la reproducción en el ámbito doméstico. Leer en las ficciones una escisión categórica entre un lugar público y otro privado, o las novelas de la democracia como la «salida de las mujeres al ámbito público», muchas veces oblitera cierta porosidad: ni las mujeres han estado antes del todo excluidas de la imaginación pública ni el rol doméstico femenino está exento de poder (Armstrong, 1987). Por eso, para interpretar las relaciones entre novelas, género y lugares se proponen tres zonas de análisis: los espacios de los mapas, los espacios de las nuevas formas de intimidad y los espacios de los vínculos de amistad entre mujeres.

Pensar a través de espacios, y no necesariamente mediante tiempos cronológicos, visibiliza que las narraciones que arman las zonas de lectura propuestas condensan en sí mismas, en sus lenguas, un tiempo que las antecede o las propulsa, y otras veces les es esquivo sólo en apariencia. En definitiva, lo que permite leer las «poéticas» (Groys, 2014) de las escritoras argentinas juntas son las fuerzas de los espacios que fundan: a modo de mapas, de nuevas formas íntimas y de imaginaciones de lo común.

\section{Escribir un mapa}

El Affair Skeffington, Bajar es lo peor y El fin de la historia fundan un territorio, con ciertos movimientos y algunas fronteras. Son novelas que interpelan a la geografía. No se trata de la cuadrícula, ni de la definición catastral, son ficciones en las que las formas de la ciudad son y no son ciudad, junto al campo de concentración como estado de excepción. Espacios y narraciones biopolíticas: la palabra de Dolly en El Affair Skeffington, la vida de Leonora — sobreviviente de un centro clandestino de detención- en El fin de la historia, la joven trasnochadora en Bajar es lo peor. Estas novelas integran el espacio - político, económico, afectivo- y procesan las voces que modulan estos mapas.

En la Argentina, desde el retorno democrático, los estudios y la militancia feminista estampan un nuevo movimiento en las vidas de mujeres y varones. El Affair Skeffington, de María Moreno -fundadora de la revista Alfonsina, primera publicación feminista del período democrático en 1983, e impulsora de El Teje, primer periódico travesti latinoamericano desde 2007- se publica en 1992. Seis años antes ocurre el primer Encuentro Nacional de Mujeres y cinco años antes se legaliza el divorcio. En 1995, Mariana Enríquez publica Bajar es lo peor, su primera novela, cuando tenía 22 años. Liliana Heker —cofundadora de las revistas literarias El escarabajo de oro, en los sesenta, y El ornitorrinco, en los setenta- publica El fin de la historia en 1996.

Ficción pionera para proponer nuevas experiencias en las vidas de mujeres, El Affair Skeffington es una escritura en capas, en la que se produce la edificación de la poeta Dolly Skeffington y de la propia María Moreno como tal — quien firma el libro con su nombre de pila Cristina Forero-. La de 
Dolly es una biografía ficcional, en los tiempos de la Rive Gauche parisina, «sobre intensidades que condensan las fuerzas afectivas de determinadas épocas» (Arnés, 2016: 30), impulsada por el hallazgo de un manuscrito con sus poemas.

También la novela de Heker y la de Enríquez proponen la construcción de una memoria biográfica ficcional de un personaje. En el caso de El fin de la historia, se trata del relato que Diana Glass construye sobre ella misma, sobre su amiga Leonora y sobre el vínculo que las une y separa a la vez, mientras que en Bajar es lo peor son las historias de un trío de amigos y parejas, dos gays y una chica, Facundo, Narval y Carolina. La novela de Heker se publica con una faja en la que se lee «Guerrilleros y militantes. La colaboración»; el texto sugiere que Leonora integra el «mini-staff» de la ESMA y que «ama» a uno de los represores que la tortura. La de Enríquez, vendida como «la novela de escritora más joven de la Argentina», está rodeada de voces que configuran narraciones de la noche, de los bares y boliches, de esa atmósfera «tétrica» (Enríquez, 1995: 784), con camperas de cuero, productos de plástico, «un compact de Soundgarden» (818), «piques» y «tipos en la puerta del kiosco, escabiando, la imagen más repetida» (796).

María Moreno y Liliana Heker comparten una temporalidad: escribir de los noventa a través de otros tiempos, el de los 20, el de los 30, el de los 70. El fin de la historia, como otras «narraciones de la traición», escenifica una polémica que, al momento de la publicación, tiene como epicentro a Buenos Aires y a Córdoba, e incorpora debates sobre la militancia de los setenta, la lucha armada y el regreso de las sobrevivientes. La apuesta de la temporalidad de Bajar es lo peor pasa por la innovación de contar a través de una chica joven un mundo cuando ese mundo todavía ni había empezado a contarse. Una novela en la que se narra, casi por primera vez, sobre esos jóvenes que pueblan luego los relatos de la afectividad de quienes «viven afuera» del mundo del Estado —entre otros, el hermano de la protagonista que padece fobia de salir a la calle-.

En estas novelas se escriben, al menos, tres mapas distintos: el de las mujeres en la época fundacional del sufragismo, las mujeres «guerrilleras» en el centro clandestino de detención, las mujeres jóvenes en el momento más álgido del reviente y la marginalidad neoliberal. Estas narraciones, cada una en sus modulaciones, comparten el procesamiento del nuevo lugar de la mujer como la imaginación, también, de un nuevo espacio ficcional. El Affair Skeffington anticipa formas que se despliegan luego: aunque el tiempo de la narración es a comienzos del siglo XX, opera una retórica sobre el tráfico de lecturas y de voces de mujeres en democracia ${ }^{2}$. En El fin de la historia esta modulación muestra cómo todo el territorio se puede volver estado de excepción: el campo de concentración es la ESMA, sí; y, a la vez, la salida a visitar a la hija mientras los militares la vigilan, el bautismo del hijo de una detenida con el represor como padrino, incluso el viaje a París. En Bajar es lo peor son las otras ruinas del estado de excepción, un mapa de economías, de medidas financieras, de circuitos de mercaderías.

\footnotetext{
${ }^{2}$ Nótese: «Hice viajar en la máquina del tiempo polémicas que comenzaban a desarrollarse en los corrillos del feminismo lesbiano durante la transición democrática, dándoles a las protagonistas contemporáneas el papel de figuras del pasado como si se tratara de un guión teatral» (Moreno, 1992: 165).
} 
Estas novelas de los noventa, leídas a través de las preguntas por los lugares, muestran la potencia de estos espacios ficcionales y ciertas cartografías que no solían contarse de esta manera a través de las mujeres. En el caso de Bajar es lo peor la novela funciona con tal fuerza como mapa afectivo que, en el prólogo a su reedición, la propia Mariana Enríquez (1995) cuenta que una lectora llega a ir al diario Página 12, donde ella trabaja, a exigir que «le marcara dónde quedaban las casas de los protagonistas, cuál era el lugar exacto del departamento donde Narval se despertaba frente al Riachuelo, dónde quedaba la casa en la que había crecido Facundo» (51).

\section{Nuevas formas íntimas}

Más que la memoria biográfica ficcional de un personaje, como en las novelas de los noventa, en las narraciones de los tempranos 2000 es la intimidad misma la que se torna pública, al modo de una táctica para darle espacio a la superexhibición de los relatos e historias que atraviesan el «yo». Este gesto no necesariamente despolitiza «las lenguas de las mujeres» sino que permite repolitizar otros materiales, otros afectos — como la belleza, el humor, la esperanza-.

En 2005 Dalia Rosetti — seudónimo de Fernanda Laguna, poeta y cofundadora del proyecto artístico-literario «Belleza y Felicidad»- publica Me encantaría que gustes de mí. Dos años después, Romina Paula —directora de teatro, dramaturga y actriz- publica su primera novela, ¿Vos me querés a mí?. En el caso de Rosetti es una suerte de road movie playera: Soledad, la protagonista, viaja a las costas de Uruguay con una amiga que compite en un torneo de surf para compartir salidas con mujeres, frustración amorosa y hasta un final trágico. En Paula, la ficción se construye mediante la escritura de diálogos -en su mayoría, reposición directa de conversaciones en forma de capítulos de brevedad vertiginosa- Inesia, la protagonista, vive y soporta su vulnerabilidad: «me doy cuenta que me cuesta tanto vivir a mí» (Paula, 2007: 88). Las dos narraciones tienen una palabra en común — «mí»— y dos significados semejantes — «gustes» / «querés»— en los que resuena esta renovada insistencia por el «yo». Este movimiento se encuadra en la discusión sobre la «autoficción», o lo que se podría nombrar también como «nuevas formas íntimas», géneros de un espacio a futuro.

Flexibilizar el lugar del género puede ser también flexibilizar los géneros, tornar plástica la lengua, su materialidad misma, mediante los giros coloquiales, las palabras entrecortadas, las onomatopeyas, la mención de marcas, las abreviaturas ${ }^{3}$. Tanto Me encantaría que gustes de mí como ¿Vos me querés a mí? trafican estos «cualquierismos» para fundar nuevos lugares para la intimidad y dinamitar las fronteras entre subjetivación y política.

Así, la escritura de Dalia Rosetti — y en esta serie se puede sumar a Romina Paula - muta en nuevas formulaciones del «yo» como «escritos éxtimos» (Palmeiro, 2011) en los que la politización de la vida privada se encuentra unida a la militancia feminista y LGBTI. Estas ficciones no reifican la noción de identidad ni cierta épica de la primera persona — «ser» mujer, «ser» lesbiana, «ser»

\footnotetext{
${ }^{3}$ Esos espacios en común en Rosetti y Paula como «iFire, fuego!» (Rosetti, 2005: 17), «permiiiiso» (28), «porsupu» (17), «uy» (121), «Coca Cola» (26), «facu» (171), «al toque» (Paula, 2007: 107), «groso» (73), «bah» (10), «ja» (29), «barbies» (94), «re» (33), entre otros.
} 
feminista - sino que ensayan la potencia de decir «yo» para contar una comunidad. Producen subjetividad para producir ciudadanía. En tanto una vida posible es una vida que se pueda relatar, abren las escrituras para que en ellas convivan, no sin fricciones, «La coleccionista, de Eric Rohmer» (Paula, 2007: 69), el festival de música electrónica «Sónar» (Rosetti, 2005: 11), «Walt Disney» (Paula, 2007: 114) y la «calentura del corazón» (Rosetti, 2005: 22).

Estos espacios de las nuevas intimidades ya se escriben sobre los mapas, esos lugares ficcionales que han sido configurados por las novelas de los noventa. En ¿Vos me querés a mí? Inesia habita sus sueños —o más exactamente sus pesadillas—, varios departamentos, el Hospital Alemán, el Hospital de clínicas, el diván de la psicóloga, el supermercado «Carrefour» y hasta se burla del concepto de «no lugar», de Marc Augé. En Me encantaría que gustes de mí se anuncia que «el mejor lugar para conseguir chicas es la playa» (Rosetti, 2005: 9). Soledad recorre bares, casinos, discos, restaurantes, rutas, hoteles. Las escrituras de Dalia Rosetti construyen mundos en los cuales todas las mujeres son «lesbianas»: las dueñas del bar, la camionera, la chica que administra los caballos. Estas lesbianas, que habían sido precursoras en el mapa de El Affair Skeffington, son ahora las ciudadanas de estas narraciones - por eso, en parte, pueden revitalizar los feminismos y proponer que si te «excitan las chicas» (Rosetti, 2005: 12) es una «fiesta» (17)—.

A partir de las formas íntimas, en El Affair Skeffington se acentúa la estrategia de enunciación: la genealogía de María Moreno se enlaza con la construcción de la poeta Dolly, en una figuración en la que Moreno escribe a Dolly para contarse a sí misma. Más que la autoría atribuida de esos poemas - a Dolly, a María, a Cristina - importa el espacio que fundan: uno de los primeros mapas de mujeres que toman la palabra, a través de la imaginación del París-Lesbos, en el que confluyen personajes como Natalie Barney, Djuna Barnes, Colette, Gertrude Stein y Anaïs Nin.

La intimidad en El fin de la historia es también el lugar de la escritura. Diana y Leonora -y hasta la propia Liliana Heker- están escribiendo a la vez: Leonora para salvar su vida - y la de los que pueda— con «la historia de la Organización» (Heker, 1996: 1572) y luego «el informe» (1836); Diana en el «taller literario» se debate cómo contar la historia de Leonora. Ellas toman la palabra. El fin de la historia hace hablar a las mujeres.

Finalmente las novelas, incluso en otras temporalidades, tienen a la democracia como un estado de la cuestión: vidas femeninas donde se puede escribir, trabajar, pasear. Mujeres públicas al punto que la auténtica «puta» en estas historias es un «chongo» (Enríquez, 1995: 516), Facundo, «quien sabía cómo enloquecer a un tipo al punto de convertirlo en un cliente devoto» (1181). La politización de la intimidad en Bajar es lo peor se inscribe en un corrimiento de lugares tal que el único trabajador sexual en estas narraciones es un varón: «-¿No pensaste nunca en [...] laburar? -Esto es lo que mejor sé hacer y, además, no deja de ser un buen laburo. [...] Sintió una punzada de dolor, como siempre que le recordaba que estaban juntos sólo por dinero» (1571). 


\section{Imaginaciones de lo común}

En El Affair Skeffington, Bajar es lo peor, Me encantaría que gustes de mí y ¿Vos me querés a mí? ninguna de las protagonistas es madre. La única que sí lo es —en El fin de la historia — inscribe una ruptura en la figura maternal tradicional: participa de acciones armadas primero; usa estrategias ante la tortura después. Ni la filialidad ni la consanguinidad son la vinculación decisiva en ninguna de estas narraciones. Casi no se mencionan las relaciones entre madres e hijos, o entre integrantes de las mismas familias. Una forma diferencial de estas novelas es que inauguran un mundo público más allá de la maternidad. Estas cinco historias habilitan los vínculos como espacios, a partir de la amistad entre mujeres, y ensayan así otras imaginaciones del estar juntas. La amistad, lazo distintivo de la vida pública, como el lugar afectivo para la democracia. ¿De qué modos estas inflexiones de la amistad femenina en las novelas posibilitan la reconfiguración de lo común que distingue a «Ni Una Menos»?

En la última década Argentina ha tenido avances políticos, jurídicos y sociales para las mujeres y la comunidad LGBTI —en particular, con la sanción de las leyes de Educación Sexual Integral (2006), Matrimonio Igualitario (2010) e Identidad de Género (2012) - Mientras tanto, cada treinta horas ocurre un femicidio -según distintas estadísticas no oficiales, como las de la organización Mumalá (Vivanco - Mumalá, 2018)—, el aborto es la principal causa de muerte materna y continúa la lucha por la legislación del trabajo sexual. En marzo de 2015 se lleva a cabo la primera maratón de lecturas contra los femicidios, con la coordinación de María Pía López —ensayista, narradora y directora, entre 2011 y 2015, del Museo del Libro y de la Lengua, dependiente de la Biblioteca Nacional- Tres meses después, tras el femicidio de Chiara Páez, es la primera convocatoria «Ni Una Menos» ${ }^{4}$.

Los feminismos argentinos no comienzan allí, sus antecedentes pueden remontarse al anarquismo y al socialismo de principios del siglo XX. «Ni Una Menos» puede leerse como esta sucesión de narraciones habilitantes, como la posibilidad construida para que esas voces ahora puedan oírse todas juntas. En palabras de Proyecto NUM, «¿fue la concentración masiva del Ni Una Menos la que produjo un cambio en el campo de lo sensible o éste se venía gestando en obras dispersas e intermitentes?» (Arnés et al., 2017: 11).

Los espacios construidos en estas novelas son parte de estas sensibilidades que laten en potencia, estos «capítulos previos» del «Ni Una Menos» que señala Giunta (2017: 21). El Affair Skeffington está dedicado a las escritoras Diana Bellessi y Mirta Rosenberg. Condensa, especialmente, las aventuras de «amigas a la manera de París-Lesbos» (Moreno, 1992: 25) en el espacio ficcional de la poeta Dolly ${ }^{5}$. Un «ajuste de cuentas» entre mujeres es también el motor de El fin de la historia. La narradora señala que es la amiga quien «hizo pedazos [su] propia historia [...] y la destruyó para siempre» (Heker,

\footnotetext{
${ }^{4}$ El femicidio de Chiara Páez, una adolescente de 14 años asesinada en Rufino (Santa Fe) impulsó la primera marcha. Según Proyecto Ni Una Menos (NUM): «Ni Una Menos fue el grito contra [esa] violencia machista que, el 3 de junio de 2015, unió a millones de personas a lo largo y ancho de Argentina (y que volvería a juntarlas un año más tarde)». A la vez, es también la «bandera» sobre la que se condensa «una nueva solidaridad entre diversos sectores sociales», las «palabras» que lo posibilitan y el motivo que da cauce a «imaginaciones llenas de futuro» (Arnés et al., 2017: 9).

${ }^{5}$ Por ejemplo, la amistad con la baronesa «cuando una llevaba a la otra al baño y la limpiaba y la vestía luego de una borrachera» (Moreno, 1992: 29).
} 
1996: 234) ${ }^{6}$. Las jóvenes que pueblan Bajar es lo peor, Me encantaría que gustes de mí y ¿Vos me querés a mí? son, ante todo, amigas. Carolina es la única sin amistades femeninas: «Nunca había conseguido tener una amistad de verdad con una mujer. Eso la hacía sentirse mucho más sola» (Enríquez, 1995: 523). En las otras novelas, Soledad es amiga de Mariela —con quien se la pasa viajando- e Inesia es la amiga de Violeta, su principal interlocutora. Los vínculos que pueden surgir en la vida pública, entre quienes se conocen en ese espacio, y las relaciones diferenciales de las mujeres entre sí son centrales para pensar en el proyecto «Ni Una Menos», como formas de imaginar comunidad.

Leer estas ficciones argentinas «a partir del género más que en el género» (Molloy, 2000) muestra que, en definitiva, las zonas de lecturas propuestas se rozan, se superponen. Estas novelas no cristalizan una discusión ya dada, son la discusión, operan como una maquinaria que expone el archivo actual, vivo, de lo que está pasando ${ }^{7}$. «Ni una Menos» son también estos relatos que le dan potencia. Estos espacios que, desde mediados de los noventa, conmocionan la vida política, económica y afectiva en estas novelas a través de la escritura de mapas, formas íntimas y vínculos de amistad entre mujeres. Narraciones que dan lugar a otros modos posibles de cruzar mundos públicos, privados e íntimos; imaginaciones, siempre, de la conmoción que está por venir.

\section{Bibliografía}

Armstrong, N. (1987): Deseo y ficción doméstica: Una historia política de la novela. Madrid, Cátedra.

ARnÉs, L. - KunAn, N. - Lumi, M. - Reissig, L. - SAlAma, E., eds. (2017): Proyecto NUM: Recuperemos la imaginación para cambiar la historia. Buenos Aires, Madreselva.

ARNÉS, L. (2016): «Ser o no ser. Cartografías afectivas en El Affair Skeffington de María Moreno», Hologramática, 24/1, pp. $21-38$.

ENRÍQUEZ, M. (1995): Bajar es lo peor. Buenos Aires, Galerna [versión ebook].

GIUnTA, A. (2017): «Genealogías de la violencia de la exclusión», en L. ARNÉs, N. KunAN, M. LuMI, L. ReISSig y E. SAlAmA, eds. (2017). Proyecto NUM: Recuperemos la imaginación para cambiar la historia. Buenos Aires, Madreselva, pp. 21-28.

GROYS, B. (2014): Volverse público: Las transformaciones del arte en el ágora contemporánea. Buenos Aires, Caja Negra.

HEKER, L. (1996): El fin de la historia. Buenos Aires, Alfaguara [versión ebook].

\footnotetext{
${ }^{6}$ Otra posibilidad de lectura sobre los vínculos entre mujeres en El fin de la historia es la «culpabilización» de la protagonista en contraposición a la santificación de aquellas que cumplen con un «mandato sacrificial» (Longoni, 2007), como «la chica de las pecas en la nariz de cuyo nombre no quiere acordarse» (Heker, 1996: 1788), un cuadro que estuvo a sus órdenes y cuando trata de «recuperarla» le responde «escucharte es mucho peor que la picana» (1810).

${ }^{7}$ Recientemente, Página 12 ha lanzado una colección del «8M» en el que se reeditan libros de María Moreno, Mariana Enríquez, Fernanda Laguna junto a otras escritoras que también modulan las voces de la democracia argentina en clave de género como Paula Pérez Alonso, Marta Dillon, Gabriela Cabezón Cámara, Selva Almada, Luciana De Mello.
} 
LONGONI, A. (2007): Traiciones: La figura del traidor en los relatos acerca de los sobrevivientes de la represión. Buenos Aires, Norma.

MACóN, C. (2015): «Giro afectivo y reparación testimonial: El caso de la violencia sexual en los juicios por crímenes de lesa humanidad», Mora, 21/1, pp. 63-87.

Molloy, S. (2000): «La flexión del género en el texto cultural latinoamericano», Revista de Crítica Cultural, 8/15, pp. 161-167.

Moreno, M. (1992): El Affair Skeffington. Buenos Aires, Mansalva, 2013.

Palmeiro, C. (2011): Desbunde y felicidad. De la Cartonera a Perlongher. Buenos Aires, Título.

PAUlA, R. (2007): ¿Vos me querés a mí? Buenos Aires, Entropía.

RANCIÈRE, J. (1998): La palabra muda: Ensayo sobre las contradicciones de la literatura. Buenos Aires, Eterna Cadencia, 2009.

RosetTi, D. (2005): Me encantaría que gustes de mí. Buenos Aires, Mansalva.

SCOTt, J. (1993): «La mujer trabajadora en el siglo XIX», en G. DuBY y M. PERROT, dirs., Historia de las mujeres en Occidente: El siglo XIX. Madrid, Taurus, pp. 405-436.

Vivanco, R. - Mumalá (2018): «47 femicidios en los primeros dos meses del año», en http://libresdelsur.org.ar/noticias/47-femicidios-los-primeros-2-meses-del-ano/ (última consulta, 5-3-2018). 